\title{
Relationship between Microstructure and Fracture Types in a UNS S32205 Duplex Stainless Steel
}

\author{
Maria Victoria Biezma ${ }^{\text {a }}$ Carlos Berlanga ${ }^{\text {b }}$, Gorka Argandona ${ }^{\text {c* }}$ \\ ${ }^{\mathrm{a}}$ Department of Earth, Materials Science and Engineering, University of Cantabria - UC, \\ Dique de Gamazo, 1, 39004 Santander, Spain \\ ${ }^{\mathrm{b}}$ Department of Mechanical, Energetic and Materials Engineering, \\ University Public of Navarra - UPNA, C/ Arrosadía s/n, 31006 Pamplona, Spain \\ ${ }^{\circ}$ Centro Multidisciplinar de Innovación y Tecnología de Navarra - CEMITEC, \\ Fundación Cetena, Polígono Mocholí, Plaza CEIN, $n^{\circ}$ 4, CP 31110 Noain, Navarra, Spain
}

Received: August 27, 2012; Revised: January 29, 2013

\begin{abstract}
Duplex stainless steels are susceptible to the formation of sigma phase at high temperature which could potentially be responsible for catastrophic service failure of components. Thermal treatments were applied to duplex stainless steels in order to promote the precipitation of different fractions of sigma phase into a ferrite-austenite microstructure. Quantitative image analysis was employed to characterize the microstructure and Charpy impact tests were used in order to evaluate the mechanical degradation caused by sigma phase presence. The fracture morphology of the Charpy test specimens were thoroughly observed in SEM, looking for a correlation between the microstructure and the fracture types in UNS S32205 duplex stainless steel. The main conclusion is the strong embrittlement effect of sigma phase since it is possible to observe a transition from transgranular fracture to intergranular fracture as increases the percentage of sigma phase. Thus, the mixed modes of fracture are predominant in the present study with high dependence on sigma phase percentages obtained by different thermal treatments.
\end{abstract}

Keywords: duplex stainless steel, sigma phase, microstructure, fractography

\section{Introduction}

Duplex stainless steels appeared as an alternative to austenitic steels for numerous components due to their excellent combination of properties such as higher strength, excellent resistance to stress corrosion cracking and localized corrosion, such as pitting and crevice. These advantages are due to a phase-balanced ferrite-austenite defect-free microstructure, but these ideal features are practically impossible due to the formation of deleterious secondary phases during high temperature processing such as hot forming, heat treatments and welding. The effect of undesired secondary phases like sigma, chi, and intermetallic precipitates principally chromium rich phases like carbides and nitrides has been widely studied ${ }^{1-5}$. Sigma phase is by far the most important secondary phase because its relatively large volume fraction produces a loss of toughness, ductility and corrosion resistance attending negotiation research spans in many disciplines ${ }^{6-11}$. Sigma phase is a hard, brittle phase, which is generally formed between 600 and $950^{\circ} \mathrm{C}$, with rapid kinetic formation; its nucleation is preferentially at the ferrite-austenite interfaces and presents different morphologies depending on thermal treatments ${ }^{12,13}$.

The chemical composition, the heat treatments, and therefore the microstructure have the most important influence on the behavior of duplex stainless steel attending the possible presence of sigma phase, since both determine

*e-mail: gorkargand@ hotmail.com the phase volume fraction and the partitioning of the main alloying elements, i.e., $\mathrm{Cr}, \mathrm{Mo}, \mathrm{Ni}, \mathrm{Mn}$ and $\mathrm{N}$. These conclusions have been the result of different studies ${ }^{14-16}$. Nevertheless, there is little information available to establish a general relationship between microstructure and fracture types in duplex stainless steels, taking account of different volumetric percentages of sigma phase into the ferrite-austenite microstructure. There are methods of application of quantitative fractography to assess the damage of duplex stainless steels with sigma phase mainly in relation to hydrogen containing environments ${ }^{17,18}$. Few studies are devoted to establish a relationship between the percentage of sigma phase into duplex stainless steels with the transition between ductile and brittle fracture in other environments ${ }^{19,20}$.

The main objective of this work was to find a relation between a ferrite-austenite-sigma phase microstructure and the fracture types in UNS S32205 duplex stainless steel. Different heat treatments were applied in order to promote the precipitation of different fractions of sigma phase. Quantitative image analysis was employed to characterize the microstructure, and Charpy impact tests were used in order to evaluate the mechanical degradation caused by sigma phase presence. The fracture types of the Charpy test specimens were thoroughly observed in SEM, looking for a correlation between the microstructure and the fracture types in the material. 


\section{Material and Methods}

The chemical composition of the samples used in the present study can be observed in Table 1:

Outokumpu provided the duplex stainless steel as a $4 \mathrm{~mm}$ wall thickness sheet. Samples cut with dimensions $250 \mathrm{~mm}$ $\times 250 \mathrm{~mm} \times 4 \mathrm{~mm}$ and $55 \mathrm{~mm} \times 10 \mathrm{~mm} \times 2.5 \mathrm{~mm}$ with a V-notch were prepared for metallographic observations and for Charpy impact tests respectively. Samples were aged in accordance with the thermal treatments at $850^{\circ} \mathrm{C}$ for 5,15 , 45 and 135 minutes followed by water quenching, in order to produce different sigma phase percentages at ferriteaustenite microstructure. Samples for optical microstructural examination were electrolytically etched in $10 \% \mathrm{NaOH}$ aqueous solution, using $2 \mathrm{~V}$ for 2 seconds. The electrolytic etching employed colours the phases as follows: ferritelight brown, austenite - white, and sigma phase - dark brown/red. The volumetric percentages of sigma phase precipitated were quantified with image analysis system using an optical microcopy at $\mathrm{x} 100$ and each value recorded an average of 50 measurements for each thermal treatment. The Charpy impact tests were carried out at room temperature. Fractographical examinations of the specimen were performed with a JEOL JSM 5600 scanning electron microscope, with a Buheler Enterprise image analyzer and Buheler MARS digital image compiler in range x200 to x2000 with EDX. These observations have been the key for establishing a relationship between microstructure and fracture morphologies.

\section{Results}

The percentage of sigma phase precipitated increases very fast with the set time at $850{ }^{\circ} \mathrm{C}$. Thus, the series of 5 , 15,45 and 135 minutes provided $1.9 \%, 14.5 \%, 18.9 \%$ and $31.1 \%$ of phase sigma respectively. Final microstructures of specimens aged at $850{ }^{\circ} \mathrm{C}$ during 15 and 45 minutes are presented in Figures 1a, b) respectively. The sigma phase nucleates at the ferrite/austenite interface and grows towards the ferrite grains; this feature has been widely studied ${ }^{2,21,22}$.

Significant changes in the impact fracture energies are observed due to the increase of phase sigma precipitated into ferrite-austenite microstructure, according the data showed in the Table $2^{23}$. Table 2 presents the values of impact energy such an average values of three samples tested. The most significant changes were produced aged at $850{ }^{\circ} \mathrm{C}$ between the time set 5-15 minutes and 15-45 minutes that implies reductions of $58.0 \%$ and $74.6 \%$ respectively.

Figure 2a) shows the fracture surfaces of as received steel with a characteristic ductile transgranular fracture mechanism, wherein a large number of deep dimples can be observed with an average size of $100 \mu \mathrm{m}$. This type of fracture morphology has been observed for other heat treatments ${ }^{24,25}$.

Figure 2b) shows the fracture morphology of samples with $850^{\circ} \mathrm{C}-5$ minutes heat treatment. The ductile fracture mode is evident again, with significant heterogeneous size dimples, $26 \mu \mathrm{m}$ average size, in the way detailed in Figure 2c). This fracture morphology is in accordance with

Table 1. Chemical composition of the UNS S32205 duplex stainless steel used in this work (balance Fe in wt.\%).

\begin{tabular}{ccccccccccc}
\hline $\mathbf{C r}$ & $\mathbf{N i}$ & $\mathbf{M n}$ & $\mathbf{M o}$ & $\mathbf{S i}$ & $\mathbf{C u}$ & $\mathbf{C e}$ & $\mathbf{N}$ & $\mathbf{C}$ & $\mathbf{P}$ \\
\hline 22.49 & 5.77 & 1.5 & 3.21 & 0.4 & 0.18 & 0.002 & 0.184 & 0.015 & 0.018 \\
\hline
\end{tabular}

Table 2. Relationship between aging time, \% sigma phase precipitated and impact energy in a 2205 stainless steel.

\begin{tabular}{lccccc}
\hline Aging time at $850{ }^{\circ} \mathrm{C}$ (minutes) & 0 & 5 & 15 & 45 & 135 \\
$\%$ sigma phase & 0 & 1.9 & 14.5 & 18.9 & 31.1 \\
Impact energy $\left(\mathrm{kJ} / \mathrm{m}^{2}\right)$ & 1925 & 1832 & 769 & 195 & 139 \\
\hline
\end{tabular}

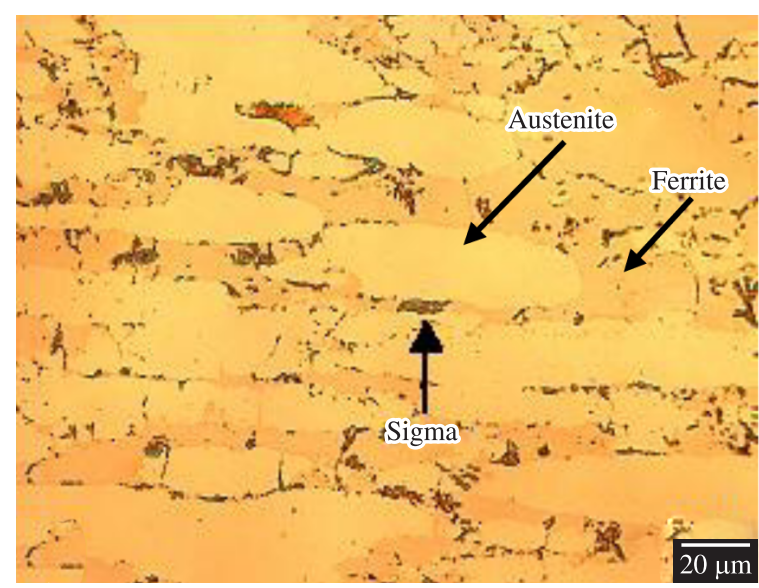

(a)

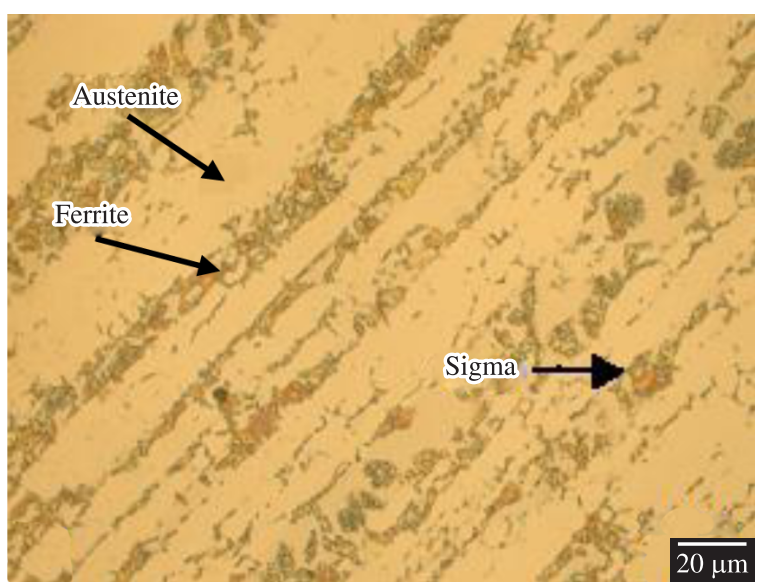

(b)

Figure 1. Microstructure of 2205 duplex stainless steel a) $850{ }^{\circ} \mathrm{C}-15$ minutes, b) $850{ }^{\circ} \mathrm{C}-45$ minutes. 


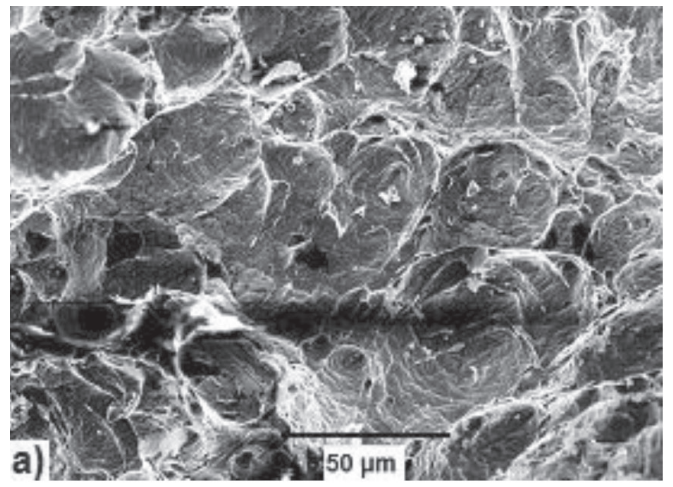

(a)

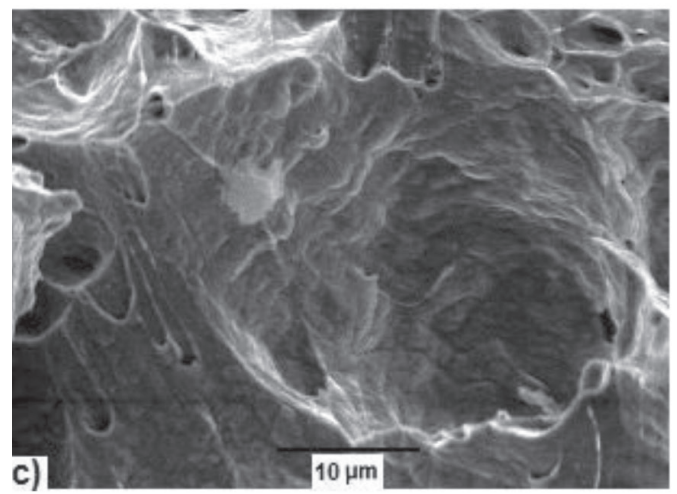

(c)

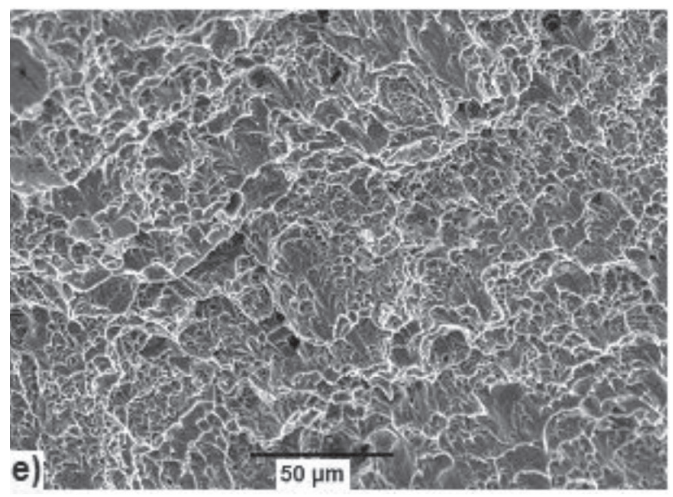

(e)

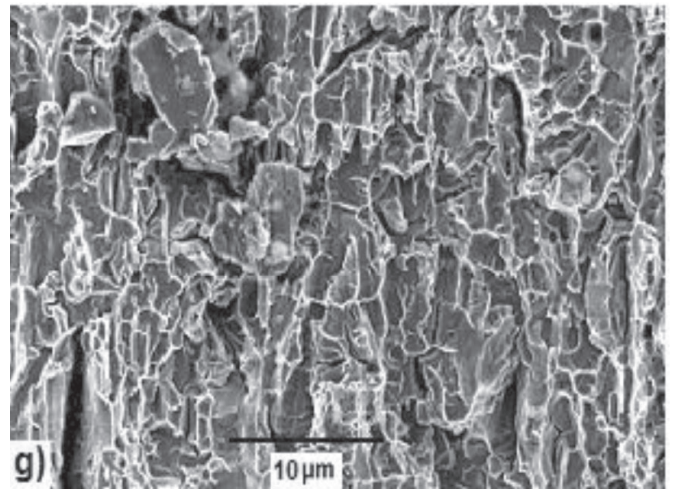

(g)

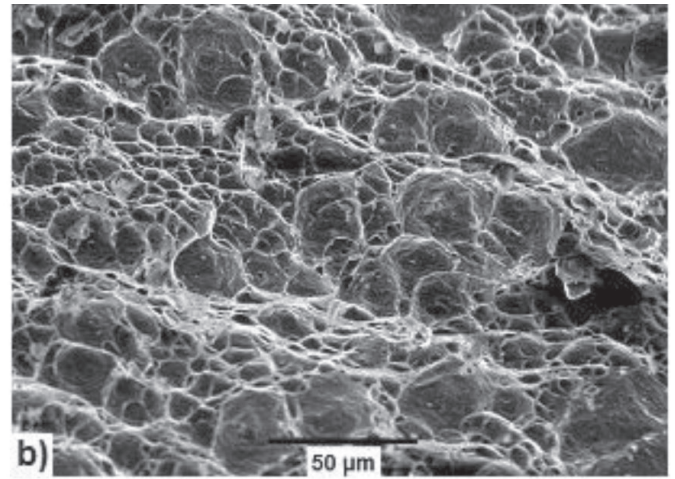

(b)

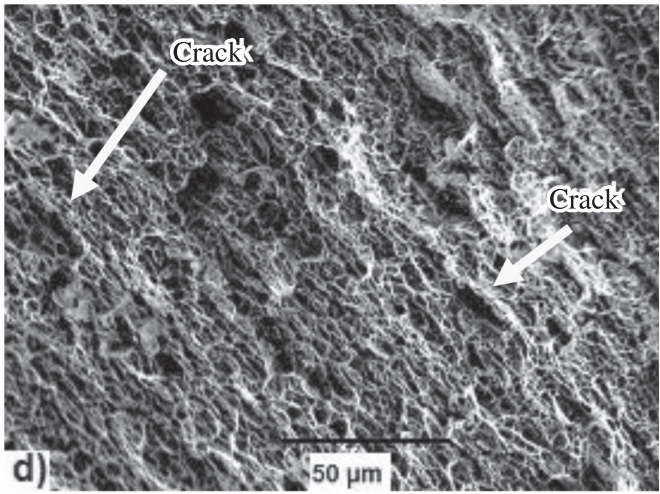

(d)

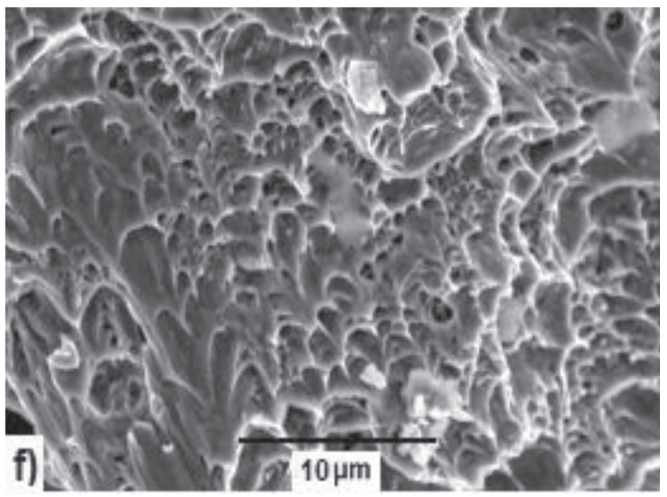

(f)

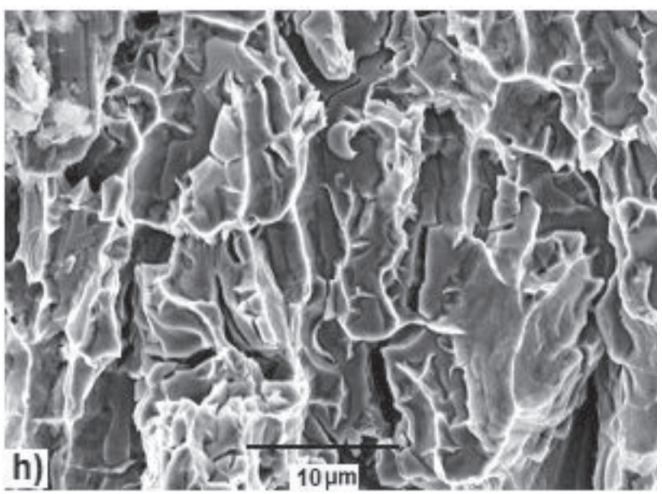

(h)

Figure 2. Fracture surfaces of 2205 duplex stainless steel. a) as received specimen, b) and c) with $850{ }^{\circ} \mathrm{C}-5$ minutes heat treatment, d) $850{ }^{\circ} \mathrm{C}-15$ minutes heat treatment, e) and f) $850{ }^{\circ} \mathrm{C}-45$ minutes heat treatment, g) and h) $850{ }^{\circ} \mathrm{C}-135$ minutes. 
Table 3. Relationship between $\%$ sigma phase precipitated and fractography in a 2205 stainless steel (*predominant).

\begin{tabular}{cl}
\hline \% sigma phase & \multicolumn{1}{c}{ Fractography } \\
\hline 1.9 & Transgranular by Coalescence Microvoids \\
14.5 & Mixed Transgranular: Coalescence Microvoids* + Quasi-cleavage \\
18.9 & Mixed: Transgranular by Quasi-cleavage* + Intergranular \\
31.1 & Intergranular \\
\hline
\end{tabular}

the high value of Charpy V impact Energy, $1832 \mathrm{~kJ} / \mathrm{m}^{2}$. Figure 2d) shows the mixed mode of ductile and brittle fracture morphology of samples with $850{ }^{\circ} \mathrm{C}-15$ minutes heat treatment. Transgranular quasi-cleavage facets are connected by shallow and elongated dimples, $5 \mu \mathrm{m}$ of average size. Cracks can be observed near quasi-cleavage facets (Figure 2d). Sigma phase causes localized tearing that form cracks. In Figure 2d, this localized tearing can be observed, pointed by the arrows, indicating the beginning of the formation of cracks. Figures $2 \mathrm{e}$ and $2 \mathrm{f}$ ) show the fracture morphology of samples with $850{ }^{\circ} \mathrm{C}-45$ minutes heat treatment. These specimens presented a significant difference in relation to former series, since the fracture type is mixed and brittle, i.e. transgranular by quasi-cleavage and intergranular fracture with the cracks traveling along the grain boundaries and near to the tear zones. Figures $2 \mathrm{~g}$ and $2 \mathrm{~h}$ show the fracture morphology of specimens with $850{ }^{\circ} \mathrm{C}-135$ minutes heat treatment. A mixed brittle fracture appears again, quasi-cleavage and intergranular fracture, being the predominant the last one. These samples presented the highest percentage of sigma phase precipitated in ferriteaustenite microstructure, $31.1 \%$, indicating an increase of $64.5 \%$ in relation to previous series.

\section{Discussion}

The fracture types evolved after Charpy $\mathrm{V}$ test depend on the sigma phase percentage promoted by different thermal treatments in the 2205 duplex stainless steel specimens. There is a clear evolution from transgranular to intergranular fracture as increases the presence of sigma phase diminishing the percentage of ferrite phase. The transgranular fracture appears in two forms: ductile as micro coalescence voids, MCV, with average dimples size decreasing with the increase of heating time, such as brittle quasi-cleavage. In addition, cracks on the fracture surface associated to microstructure with $14.5 \%$ of phase sigma precipitated have been observed.

The most critical is $850{ }^{\circ} \mathrm{C}-45$ minutes thermal treatment with $18.9 \%$ sigma precipitated since it produces a critical change in the fracture types: disappears transgranular fracture by microcoalescence voids and coexists transgranular cleavage or quasi-cleavage facets with intergranular fracture. For 45 minutes the former one is the predominant and for 135 minutes, with $31.1 \%$ of sigma phase precipitated, the last one fracture type is the predominant, Figure $3 \mathrm{~h}$. Thus, fractografical examinations have revealed that the increase of sigma phase precipitated into a 2205 duplex stainless steel has produced a change of the fracture type from transgranular mode, ductile $100 \%$ microcoalescence voids to mixed brittle, quasi-cleavage and intergranular mode. In addition, the mixed modes of fracture are predominant in the present study. Table 3 summarizes the percentage of sigma phase precipitated and its effect on fracture modes in a 2205 duplex stainless steel.

\section{Conclusions}

The effect of sigma precipitation on Charpy $\mathrm{V}$ impact energy is very significant for thermal treatment at $850{ }^{\circ} \mathrm{C}$ in the time interval between 5 an 15 minutes (associated with a percentage of sigma phase between $1.9 \%$ and $14.5 \%$ ). The increase of $1.9 \%$ to $31.1 \%$ percentage of sigma phase precipitated implies very important changes in the failure type: transcrystalline type mode by micro coalescence voids to transgranular by quasi-cleavage and intergranular fractures. The most critical is the $850{ }^{\circ} \mathrm{C}$ - 45 minutes thermal treatment. Thus, the mixed modes of fracture are predominant in the present study with high dependence on sigma phase percentages obtained by different thermal treatments. It is necessary a study in depth to conclude which percentage of sigma phase causes the transition from ductile to mixed fracture.

\section{Acknowledgements}

The authors would like to acknowledge to Outokumpu for giving us the 2205 duplex stainless steels and to the Prof. Suárez and their Research Group on Hybrid Materials of Universidad Politécnica of Madrid, Spain, for facilitating us with the use of Scanning Electron Microscopy. 


\section{References}

1. Huang CS and Shih CC. Effect of nitrogen and high temperature aging on $\sigma$ phase precipitation of duplex stainless steel. Materials Science and Engineering. 2000; A 402:66-75.

2. Sieurin $H$ and Sandström R. Sigma precipitation in duplex stainless steel 2205. Materials Science and Engineering. 2007; A444: 271-276.

3. Chen TH and Yang JR. Effects of solution treatments and continuing cooling on sigma-phase precipitation in a 2205 duplex stainless steel. Materials Science and Engineering. 2001; A: 311:28-41.

4. Sathirachinda N, Pettersson R, Wessman S and Pan J. Study of mobility of chromium nitrides in isothermally aged duplex stainless steels by using SKPFM and SEM/EDS. Corrosion Science. 2010; 52:179-186. http://dx.doi.org/10.1016/j. corsci.2009.08.057

5. May JE, Souza CAC, Nascente PAP, Soares P, Lepienski $\mathrm{CM}$ and Kuri SE. Effect of thermal aging conditions on the corrosion properties and hardness of a duplex stainless steel. Materials Research. 2010, 13(4):431-436. http://dx.doi. org/10.1590/S1516-14392010000400003

6. Do Nascimiento AMN, Ierardi MCF, Kina AY and Tavares SSM. Pitting corrosion resistance of cast duplex stainless steels in $3.5 \% \mathrm{NaCl}$ solution. Materials Characterization. 2008; 59: 1736-1740. http://dx.doi. org/10.1016/j.matchar.2008.03.015

7. Wilms ME, Gadgil VJ, Krougman JM and Kolster BH. Effect of $\sigma$-phase precipitation at $800{ }^{\circ} \mathrm{C}$ on the mechanical properties of a high alloyed duplex stainless steel. Materials High Temperaures. 1991; 9:160-166.

8. Nilsson JO, Kangas P, Karlsson T and Wilson A. Mechanical properties, microstructural stability and kinetics of $\sigma$ phase formation in $29 \mathrm{Cr}-6 \mathrm{Ni}-2 \mathrm{Mo}-0.38 \mathrm{~N}$ in super duplex stainless steel. Metallallurgical Materials Transactions. 2000; A 31:3545.

9. Lopez N, Cid M and Puiggali M. Influence of sigma phase on mechanical properties and corrosion resistance of duplex stainless steels. Corrosion Science. 1999; 41:1615-1631. http:// dx.doi.org/10.1016/S0010-938X(99)00009-8

10. Sáenz L, Plaza L, Ocando A and Grippi L. Estudio de la fragilización del acero inoxidable dúplex SAF 2205 envejecido. Revista Ingeniería UC. 2007; 14(3): 68-76.

11. Fargas G, Mestra A, Anglada M and Mateo A. Influencia de la fase sigma en la resistencia al desgaste de los aceros inoxidables dúplex. Anales de Mecánica de la Fractura 26. 2009; 1:160-165.

12. Pohl M, Storz OT and Glogowski T. Effect of sigma-phase morphology on the properties of duplex stainless steel. Microscopy Microanalysis. 2005; 11:230-231. http://dx.doi. org/10.1017/S1431927605505889

13. Lo KH, Kwok CT and Chan WK. Characterisation of duplex stainless steel subjected to long-term annealing in the sigma phase formation temperature range by the DLEPR test. Corrosion Science. 2011; 53:3697-3703. http://dx.doi. org/10.1016/j.corsci.2011.07.013

14. Kaçar R and Acarer M. Microstructure-property relationship in explosively welded duplex stainless steel-steel. Materials Science and Engineering: A. 2003; 363:290-296. http://dx.doi. org/10.1016/S0921-5093(03)00643-9

15. Gosh SK and Mondal S. High temperature ageing behavior of a duplex stainless steel. Materials Characterization. 2008; 59:1776-1783. http://dx.doi. org/10.1016/j.matchar.2008.04.008

16. Josefsson B, Nelsson J and Wilson A. Phase transformations in duplex steels and the relation between continuous cooling and isothermal heat treatment. In: Proceedings of the 91st Conference Duplex Stainless Steel; 1991; Beaune, France. Beaune; 1991. v. 1, p. 67-78.

17. Michalska J, Sozanka M and Hetmanczyk M. Application of quantitative fractography in the assessment of hydrogen damage on duplex stainless steel. Materials Characterization. 2009; 60:1100-1106. http://dx.doi. org/10.1016/j.matchar.2009.05.005

18. Kuroda T. Role of sigma phase on hydrogen embrittlement of super duplex stainless steels. Transactions of JWRI. 2005; 34:63-68.

19. Li J, Wu T and Riquier Y. Sigma phase precipitation and its effect on the mechanical properties of a super duplex stainless steel. Materials Science and Engineering: A. 1994; 174:149-156. http://dx.doi.org/10.1016/0921-5093(94)91083-9

20. Borvik T, Lange H, Marken LA, Langseth M, Hopperstad OS, Aursand M et al. Pipe fittings in duplex stainless steel with deviation in quality caused by sigma phase precipitation. Materials Science and Engineering: A. 2010; 527: 6945-6955. http://dx.doi.org/10.1016/j.msea.2010.06.087

21. Magnabosco R. Kinetics of sigma phase formation in a duplex stainless steel. Materials Research. 2009; 12:321-327. http:// dx.doi.org/10.1590/S1516-14392009000300012

22. Michalska J and Sozańska M. Qualitative and quantitative analysis of $\sigma$ and $\chi$ phases in 2205 duplex stainless steel. Materials Characterization. 2006; 56:355-362. http://dx.doi. org/10.1016/j.matchar.2005.11.003

23. Berlanga C, Moreira F, Leal J, Santos H and Biezma MV. Degradación de propiedades de un acero inoxidable dúplex debida a la precipitación de fase sigma. In: Proceedings of the XI Congreso Nacional de Materiales; 2010; Zaragoza, Spain. Zaragoza; 2010. p. 343.

24. Martins M, Rossitti SM, Ritoni M and Casteletti LC. Effect of stress relief at $350^{\circ} \mathrm{C}$ and $550^{\circ} \mathrm{C}$ on the impact properties of duplex stainless steels. Materials Characterization. 2007; 58:909-916. http://dx.doi.org/10.1016/j.matchar.2006.09.006

25. Ibrahim OH, Ibrahim IS and Khalifa TAF. Effect of Aging on the toughness of austenitic and duplex stainless steel weldments. Journal of Materials Science and Technology. 2010; 26:810-816. http://dx.doi.org/10.1016/ S1005-0302(10)60129-6 